\title{
Developing a daily indicator for evaluating the impacts of tourism in isolated regions
}

\author{
Mohcine Bakhat $^{1}$, Jaume Rosselló ${ }^{1 \star}$ and Oscar Sáenz-de-Miera ${ }^{1}$
}

Submitted: 08/03/2010 Accepted: 16/07/2010

\footnotetext{
${ }^{1}$ Centre de Recerca Econòmica, Departament d'Economia Aplicada, Universitat de les Illes Balears, Carretera Valldemossa km 7.5, 07122 Palma de Mallorca, Spain

*Corresponding author; e-mail: jrossello@uib.es
}

\section{(c) 2010 International University College. All rights reserved}

Citation: Bakhat M., J. Rosselló, O. Sáenz-de-Miera (2010) Developing a daily indicator for evaluating the impacts of tourism in isolated regions. European Journal of Tourism Research 3(2), pp. 114-118

\section{Introduction}

During the last years the tourism industry has witnessed an extraordinary growth which has been accompanied by a substantial increase in environmental costs and other detrimental externalities which are associated with a high influx of tourists. The literature has been able to develop different techniques to evaluate and appraise the positive economic impacts associated with tourism (Tourism Satellite Accounts and General Equilibrium Models, mainly), however, the methodological deficits when appraising the negative impacts persist. It has been recognized that in order to assess and improve sustainable development, analyses of a sector's performance should not only address its economic contributions but also environmental and social dimensions (Gray and Bebbington 1993; Brida et al. 2008; Martin 2009). In response to this recognition, additional methods for auditing performance have evolved, including lifecycle assessment (Hernández and León 2007; Becken and Simmons 2008) and ecological footprinting (Gössling, Borgström Hansson, Hörstmeierc and Saggeld 2002; Patterson Niccolucci and Bastianoni 2007).

114
Although researchers agree that the environmental impacts of tourism are substantial (Gössling, 2002), the literature has only recently begun to analyze the direct environmental effects of tourist activities. For instance, tourism is responsible for a large proportion of national energy consumption from activities associated with transportation and services rendered at the destination (Becken, 2002; Becken and Simmons, 2002, Becken et al, 2001, 2003; Gossling, 2000; Gossling et al, 2002; Tabatchnaia-Tamirisa et al, 1997). For this reason, it is important to highlight the main economic sectors that are associated with tourism including transportation and/or accommodation. This perspective can be better understood by the nonexistence of a touristic sector in the traditional economic classifications on National Accounts. However, it should be noted that in applying tourism policies, public administration officials should attribute the environmental and social costs of tourism to the industry as a whole and not only to the most representative economic sectors.

In order to deal with this problem the United Nations have developed the tourism satellite 
account (TSA) which helped to measure the true size of the tourism industry and to show that tourism constitutes a significant part of the overall economy instead of just being a minor economic player. The TSA's rely on extracting tourism-related economic activities from existing systems of economic accounts, and generally cover only the direct effects of tourism expenditure in tourism-related industries. Another alternative approach to measure the economic impact of tourism, which may be labelled "visitor survey method", relies on a more direct estimation of tourism volumes and expenditure via formal visitor surveys. Survey methods often use regional economic tools, such as input-output models and multipliers to convert tourist expenditure into the associated income and jobs and to estimate secondary impacts (multiplier effects). However, although these approaches might be valid when economic impact is evaluated, they fail when other kind of impacts have to be measured.

Based on the definition of tourism and in order to consider it as an aggregate, a researcher may opt for tourist arrivals as an indicator of pressure and different impacts. Nevertheless, this approach, often available through monthly data, presents two main drawbacks. Firstly, for the tourist imputation to a certain month, the presence of a time lag between the arrival date and the day when a tourist is effectively impacting could result in a bias, and particularly when including tourists arriving at the end of the month. Secondly, and due to tourism patterns which may change over the years or during the same year, the length of stay could be affected and, hence, its omission in the analysis could largely affect the estimated results.

In this context, this research note aims to develop a measure of tourist pressure capable of being related to most environmental indicators and other socioeconomic indicators overcoming the limitations of the simple use of monthly aggregated tourist arrivals. Using daily data, the indicator is developed and computed for the case study of the Balearic Islands (Spain), one of the most important Mediterranean resort destinations that can benefit from their geographical nature when the indicator has to be implemented.

\section{Methodology}

From a practical point of view, one of the most important advantages that characterize islands is that all tourists arrive by plane or by boat, thus simplifying controls and statistics. Using this special feature, Riera and Mateu (2007) develop a daily indicator of human pressure (DIHP) quantifying the demographic burden that an isolated territory supports at a given day using the case study of the Balearic Islands.

The methodology for computing the DIHP takes as a reference point the amount of people of the first day of each year $\left(P_{0}\right)$ as the sum of the resident population $\left(R P_{0}\right)$ and the amount of tourists $\left(T P_{0}\right)$. Then, for each one of the following days, the daily balance of people between arrivals $\left(A_{t}\right)$ and departures $\left(D_{t}\right)$ is added as well as an estimation of the population growth $\left(V_{t}\right)$, which is a consequence of the "natural" evolution of the population for any given period $(t)$, in this case a day. Analytically:

$$
\operatorname{DIHP}_{t}=P_{0}+\sum_{t=1}^{365}\left(A_{t}-D_{t}\right)+\sum_{t=1}^{365} V_{t}
$$

Although this equation summarizes the basic idea of the daily population pressure evidencing, for instance, great differences between summertime and wintertime in the Balearic Islands (Riera and Mateu, 2007), an additional improvement can be considered in order to discriminate between tourist and resident population. Thus, if the amount of residents who are not present on the territory $\left(R P O_{t}\right)$ is isolated, the DIHP can be expressed as:

$$
D I H P_{t}=T P_{0}+\sum_{t=1}^{365}\left(A_{t}-D_{t}\right)+R P_{0}+\sum_{t=1}^{365} V_{t}-R P Q
$$

Where the resident population present on the territory at a given day $\left(R P_{t}\right)$ can be identified as: 
Developing a daily indicator for evaluating the impacts of tourism in isolated regions.

$$
R P_{t}=R P_{0}+\sum_{t=1}^{365} V_{t}-R P O_{t}
$$

Then, the tourist population present on the territory at a given day $\left(T P_{t}\right)$ can be calculated from:

$$
T P_{t}=D I H P_{t}-R P_{t}
$$

It should, thus, be noted how the daily stock of people in a given day on a territory can be split into the daily stock of residents in a given day and the daily stock of tourists in a given day. Analytically:

$$
D I H P_{t}=R P_{t}+T P_{t}
$$

\section{Application}

The case study of the Balearic Islands (Spain) is analyzed because of the special importance of tourism in the archipelago (with more than 13 millions of tourists and 1 million of inhabitants in 2008), which has motivated different tourism impact analyses and also due to the geographical characteristics of the islands' territories that facilitate the computation of the stock measures. The Balearic Islands are located in the West of the Mediterranean Sea and are composed by four populated islands: Mallorca, the biggest one, which absorbs more than $75 \%$ of tourism arrivals; Menorca with less than $10 \%$, and Eivissa and Formentera (known jointly as the Pitiüses, and sharing one single airport located in Eivissa) with more than a $15 \%$ of the total arrivals of the archipelago. Tourists in the Balearic Islands usually belong in the medium or medium-low income brackets and their principal motivations are related to climate and beaches, a circumstance that explains why tourism in the islands has a high degree of seasonality, with more than a $60 \%$ of tourist arrivals concentrated from June to September.

Using data collected from the $1^{\text {st }}$ of January 2002 to $31^{\text {st }}$ of December 2008, the computation of the DIHP of the Balearics takes the resident population of the first day of each year $\left(R P_{0}\right)$ from the municipal register that can be downloaded from the national statistical institute (INE - Instituto Nacional de Estadística, http://www.ine.es). The amount of tourists during the first day of the year $\left(T P_{0}\right)$ is estimated using the statistics of the "Hotel Occupancy Survey" and "Apartment Occupancy Survey" (also accessible from INE) and an estimation of the tourists lodged in other typology of accommodation (i.e. friends or relatives) from the international tourism survey for Spain (Frontur) elaborated by the Institute for Tourism Studies. Daily arrivals $\left(A_{p}\right)$ and daily departures $\left(D_{p}\right)$ are derived from passenger transit at ports and airports, and were provided by AENA, the Spanish national airport manager. $V_{p}$ is calculated under the assumption that the probability of either being born or dying is the same for every day of the year; hence, it is derived from dividing the natural population growth by 365 . Finally, since the domestic tourism survey of the Spanish residents (Familitur) collects monthly information on Spanish people travelling abroad (domestic and international trips), a monthly estimation of the residents outside the Balearics is accessible, with the possibility of obtaining the daily estimation of residents not present on the islands $\left(R P_{t}\right)$ by using the mean length that is already available from the same survey.

All the variables mentioned above are available for each one of the islands with the exception of $R P_{t}$. In this case, an indicator for each one of the main islands can be obtained and the amount of resident population abroad has to be estimated using the weight of resident population for each island and, then, assuming that the travel propensity is the same for all the residents.

Thus, using the data mentioned above, the decomposition of the DIHP into tourist population stock (TP) and resident population stock $(R P)$, for the entire archipelago (BAL) and each one of the main islands, Mallorca (MALL), Menorca (MEN) and Pitiüses (PIT) (that includes Eivissa and Formentera), is shown in Figure 1. 

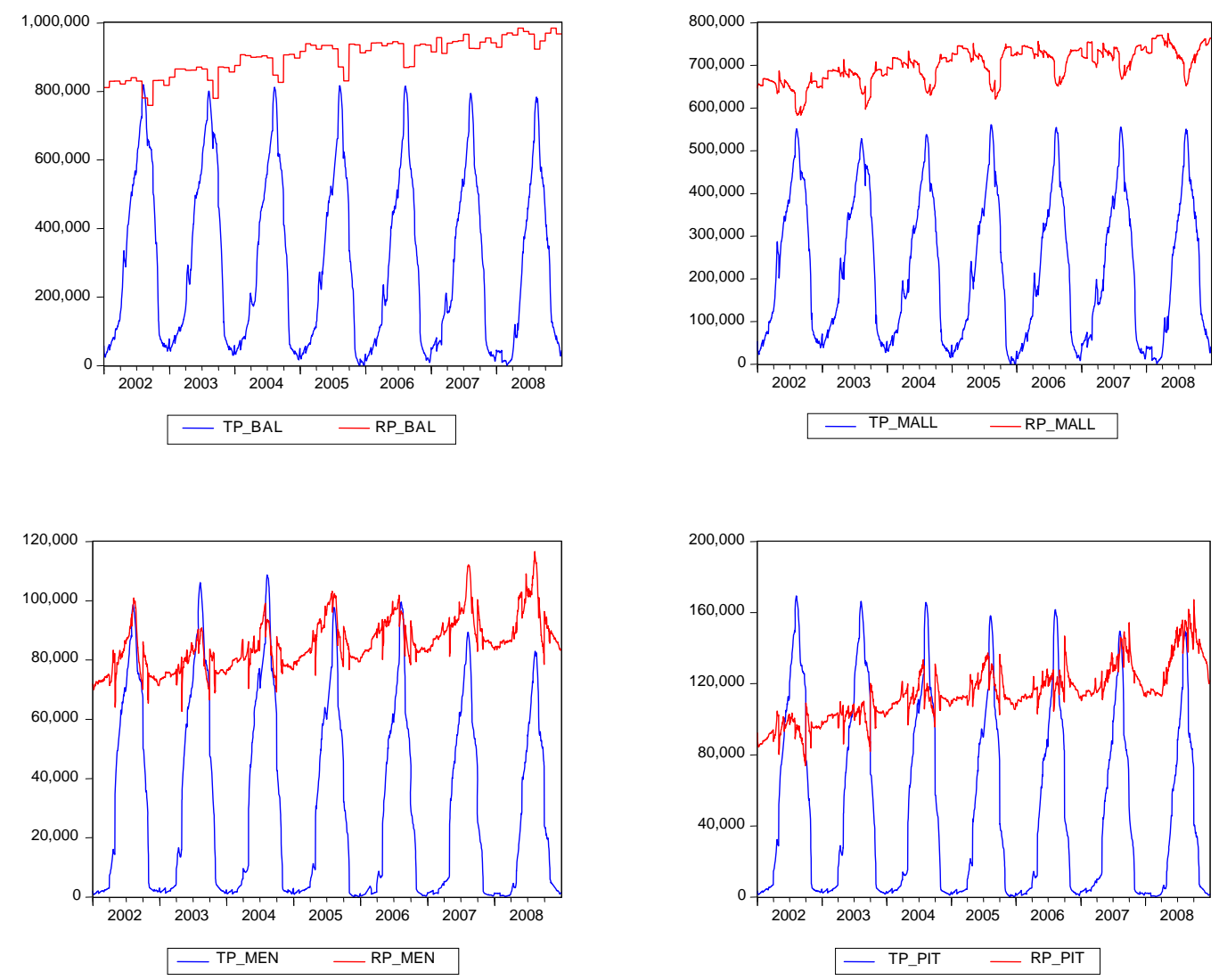

\section{Figure 1: Daily tourist and resident stock of population}

Through the calculation of the TP and $R P$ variables it is shown how tourism is responsible for the strong seasonal component shown in the DIHP. Meanwhile, the residents, following their usual practices, tend to take their holidays during summertime too, reducing their presence during the peak months. Moreover, from a regional point of view, it can be seen how in the cases of Menorca and Pitiuses, the number of tourists during some weeks is even higher than that of residents, al least during the first few years of the sample.

\section{Conclusion}

The possibility to apply tourism policies in public administrations is a fact, and this reason explains why different efforts (Tourism satellite accounts, visitor's expenditure surveys) have been made in the last years in order to compute the economic significance of tourism. However, since tourism development entails other environmental and social costs and it becomes necessary to ascribe the responsibility of the tourist activity as a whole and not only of its most representative economic sectors, this research note has developed a new indicator to be used as a reference for tourism pressure.

Assessing environmental impacts is essential if tourism is to become a more sustainable activity. Thus, it is important to ascertain the magnitude of environmental impacts and their associated costs as a means of determining appropriate development strategies and solutions. Literature reveals that the costs associated with tourism have been evaluated from a sectoral perspective, given the nonrecognition of the tourist sector in conventional public economic accounting, and this perspective can provide biased conclusions for 
the sectors involved, penalizing accommodation and transport sectors as the most frequently related sectors.

A new indicator, that can be related to externalities and other environmental impacts from a temporal point of view, has been developed using the geographical opportunity that isolated territories, like islands, bring from a statistical point of view. This methodology improves the simple use of the number of tourists by considering (instead of estimating) their length of stay and developing a daily indicator for tourists and residents stocks. Future research should be aimed at developing models of energy demand, water consumption, public health services, urban waste production, etc., including the measure developed in this paper in order to estimate the role of tourism in the determination of such models and to evaluate the exportability of the results for nonisolated regions.

\section{References}

Becken, S. (2002) Analysing international tourist flows to estimate energy use associated with air travel. Journal of Sustainable Tourism 10(2), 114-131.

Becken, S., D. Simmons (2002) Understanding energy consumption patterns of tourist attractions and activities in New Zealand. Tourism Management 23(4), 343-354.

Becken, S., and D. Simmons (2008) Using the concept of yield to assess the sustainability of different tourist types. Ecological Economics 67(3), 420-429.

Becken, S., C. Frampton, D. Simmons (2001) Energy consumption patterns in the accommodation sector - the New Zealand case. Ecological Economics 39(3), 371-386.

Becken, S., D. Simmons, and C. Frampton (2003) Energy use associated with different travel choices. Tourism Management 24(3), 267-277.
Brida, J.G., E.J. Sanchez and E. Accinelli (2008) Preservation of environmental quality and tourist investments. European Journal of Tourism Research 1(1), 3-15.

Gray, R., J. Bebbington (1993) Accounting for the Environment. London: Sage.

Gössling, S. (2000) Sustainable tourism development in developing countries: Some aspects of energy use. Journal of Sustainable Tourism 8(5), 410-25.

Gössling, S. (2002) Global environmental consequences of tourism. Global Environmental Change 12(4), 283-302.

Gössling, S., C. Borgström Hansson, O. Hörstmeier, S. Saggel (2002) Ecological footprint analysis as a tool to assess tourism sustainability. Ecological Economics 43(2-3), 199-211.

Hernández, J.M., and C. León (2007) The interactions between natural and physical capitals in the tourist lifecycle model. Ecological Economics 62(1), 184-193.

Martín, I. (2009) Economic development versus environmental sustainability: The case of tourist marinas in Andalusia. European Journal of Tourism Research 2(2), 162177

Patterson, T. M., V. Niccolucci, S. Bastianoni (2007) Beyond 'more is better': Ecological footprint accounting for tourism and consumption in Val di Merse, Italy. Ecological Economics 62(3-4), 747756.

Riera, A., J. Mateu (2007) Aproximación al volumen de turismo residencial en la Comunidad Autónoma de las Illes Balears a partir del cómputo de la carga demográfica real. Estudios Turísticos 174, 59-72.

Tabatchnaia-Tamirisa, N., M. K. Loke, P. Leung, K.A. Tucker (1997) Energy and tourism in Hawaii. Annals of Tourism Research 24(2), 390-401. 